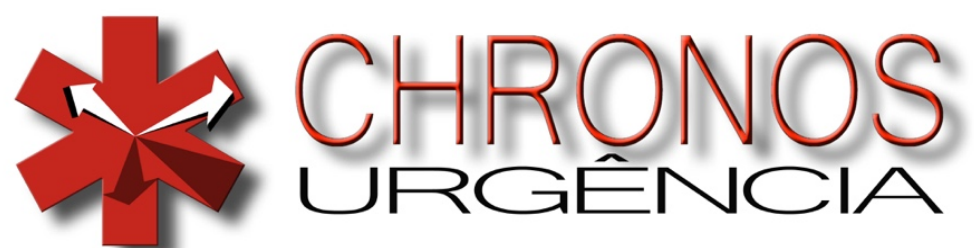

https://chronos.samu.fortaleza.ce.gov.br elSSN 2763-5872

\title{
Artigos
}

\section{Avaliação de Competências em Suporte Básico de Vida em Serviço de Atendimento Móvel de Urgência}

\author{
Evaluation of Competencies in Basic Life Support in Mobile Emergency \\ Service (abstract: p. 15)
}
Evaluación de Competencias en Soporte Vital Básico en Servicio Móvil
de Emergencias (resumen: p. 15)

\section{CLÁUDIO ROBERTO FREIRE DE AZEVEDO}

claudio.azevedo@samu.fortaleza.ce.gov.br

Núcleo de Educação Permanente do SAMU 192 - Regional Fortaleza

Rua Padre Guerra, 1350; Parquelândia. Fortaleza - Ceará CEP 60.455-365

(iD) JULIANA ARAÚJO DE MEDEIROS

jumedeiros@orion.med.br

Núcleo de Educação Permanente do SAMU 192 - Regional Fortaleza

\section{JULYANA GOMES FREITAS}

julyana.freitas@unifor.br

Universidade de Fortaleza / Núcleo de Educação Permanente do SAMU 192 - Regional Fortaleza

WILCILENE OLIVEIRA DOS SANTOS

wilcilene_oliveira@hotmail.com

Núcleo de Educação Permanente do SAMU 192 - Regional Fortaleza

\section{CLÁUDIA REGINA DE CASTRO LIMA}

claudiasamu192@gmail.com

Núcleo de Educação Permanente do SAMU 192 - Regional Fortaleza

Objetivo: relatar a experiência de avaliação diagnóstica de competências no suporte básico de vida prestado pelos condutores e técnicos de enfermagem do SAMU 192, em Fortaleza. Metodologia: estudo descritivo, de abordagem qualitativa, do tipo relato de experiência sobre avaliação de competências realizada com 193 profissionais, a fim de verificar as competências técnicas destes sobre suporte básico de vida, em fevereiro de 2015, em 3 estações, contemplando o atendimento ao trauma, reanimação cardiopulmonar e procedimentos de segurança. Resultados: participaram 130 profissionais (67,4\% do total); 63 não se disponibilizaram à avaliação. Aqueles que compareceram perfizeram um total de 368 avaliações, pois alguns não realizaram as três estações (chamados para ocorrências, desistências e resistências); somente 27 (20,8\%) obtiveram conceito satisfatório em todas as estações e 73 (56,1\%) obtiveram satisfatório somente em uma ou em nenhuma estação. Percebeu-se melhor qualificação dos condutores, em relação aos técnicos de enfermagem. Foram observados incidentes críticos na avaliação diagnóstica. Considerações finais: foram evidenciadas as fragilidades do serviço no âmbito técnico-administrativo (formas de atendimento e fluxos de trabalho), mas também nos aspectos afetivo-atitudinais, pessoais ou interpessoais. Como consequência, planejou-se uma total reformulação dos processos educacionais na implementação da educação permanente no serviço.

Descritores: Avaliação Educacional; Educação Permanente; Serviços Médicos de Emergência.

Palavras-chave: Avaliação; Educação Permanente; Educação Popular em Saúde; Competências; Urgência; Pré-hospitalar.

Azevedo CRF, Medeiros JA, Freitas JG, Santos WO, Lima CRC. Avaliação de Competências em Suporte Básico de Vida em Serviço de Atendimento Móvel de Urgência. Rev. Chronos Urg. 2021; v.1 n.1: e1121.9

https://doi.org/10.52572/revchronosurg.v1i1.9 


\section{Introdução}

O serviço de atendimento pré-hospitalar em Fortaleza, idealizado em 1991, iniciou suas atividades em 15 de junho de 1.992, embora tenha sido oficializado como Programa S.O.S Fortaleza somente em 23 de junho de 1992, por meio do Decreto $N^{\circ}$ 8.818, com a criação de sua Comissão Coordenadora ${ }^{1}$. À época, o serviço funcionava somente com equipes de Suporte Básico de Vida (SBV) em ambulâncias tripuladas por auxiliares de enfermagem e condutores capacitados para o serviço. A regulação das ocorrências ficava sob a responsabilidade de um profissional enfermeiro que priorizava os chamados.

O lançamento do SAMU 192 - Fortaleza na assistência pré-hospitalar de urgência, em substituição ao já então Núcleo S.O.S. Fortaleza, é anunciado pelo Ministro da Saúde Humberto Costa em Fortaleza em 17 de novembro de 2003, mas sua habilitação municipal pelo Ministério da Saúde somente se dá oficialmente na Portaria SAS/MS N 307, de 03 de março de 2004¹.

Apesar de sua área de abrangência ser municipal o mesmo tem porte de regional, baseado na Portaria GM/MS № 2.026, de 24 de agosto de $2011^{1}$. Assim, pela Portaria GM/MS № 2.502, de 1ㅇ de novembro de 2012, o SAMU 192 - Fortaleza é habilitado pelo Ministério da Saúde como "SAMU 192 - Regional Fortaleza" (SAMUFor) ${ }^{1}$. Sua qualificação vem somente depois, pela Portaria GM/MS № 1.116, de 27 de abril de $2018^{1}$. Atualmente trabalha com 32 equipes: seis de suporte avançado, duas de suporte intermediário, 16 de suporte básico e uma de apoio às urgências em saúde mental, quatro motolâncias e três bicicletas².

Desde o início do funcionamento do Programa S.O.S. Fortaleza já havia uma estrutura municipal de educação para o atendimento pré-hospitalar denominada Centro de Formação em Urgência (CEFUR). O CEFUR preparava profissionais para o ingresso no Programa S.O.S. Fortaleza e, após admitidos, trabalhava com o conceito de educação em serviço ${ }^{3}$ : capacitações específicas e sessões clínicas com temas decididos pela gestão, com palestrantes convidados a falar de temas específicos. Treinamentos da American Heart Association e do American College of Surgeons também eram oferecidos a todos os profissionais do serviço, como forma de qualificação dos mesmos, visando impacto direto na meIhoria da qualidade do atendimento prestado.

Com a publicação das Portarias GM/MS № 2048, de 05 de novembro de $2002^{1}$, e № 1863 , de 29 de setembro de $2003^{1}$, essa última implantando a Política Nacional de Atenção às Urgências (PNAU), definiu-se, a nível nacional, a criação de estruturas regionais de educação voltadas à capacitação dos profissionais da urgência: os Núcleos de Educação em Urgências (NEU).

Os NEU teriam a problematização como modelo pedagógico para o ensino do atendimento às urgências em todos os níveis de atenção, primário, secundário e terciário, redefinidos agora, em 
termos de urgência, como atenção pré-hospitalar fixa, pré-hospitalar móvel, hospitalar e pós-hospitalar. Seu modelo pedagógico deveria também abranger, em seu escopo, todos os demais pressupostos da Educação Permanente (EP), posto que teria que estar alicerçado nos polos de educação permanente em saúde.

Diante desse grande desafio, e inúmeras dificuldades a nível nacional para concretizá-lo, em março de 2006, por ocasião do I Congresso Nacional da Rede SAMU 192 promovido pelo Ministério da Saúde, foi proposto que cada SAMU centrasse esforços na implantação de seu núcleo específico, doravante denominado Núcleo de Educação Permanente (NEP), com o principal objetivo de promover a educação dos profissionais do componente pré-hospitalar móvel, recertificando-os a cada dois anos, como previsto no Capítulo VII, item 1.4 da citada Portaria GM/MS № 2048/2002.

Com a publicação da Política Nacional de Educação Permanente em Saúde ${ }^{4}$ e de suas diretrizes de implementação, constantes na Portaria GM/MS № 1996, de 20 de agosto de $2007^{5}$, vai ficando cada vez mais claro para a gestão do SAMU 192 - Fortaleza que o seu setor educacional não conseguia fazer EP, nem tinha profissionais capacitados para tal.

A EP é a aprendizagem no trabalho, incorporada ao cotidiano das organizações. Baseia-se na aprendizagem significativa e na possibilidade de mudanças nas relações, nos processos, nos atos de saúde e nas pessoas, transformando as práticas de atenção, gestão e educação a partir da "problematização" do processo de trabalho ${ }^{6}$ e do diálogo sobre essas experiências ${ }^{7}$. Costuma ser trabalhada com metodologias ativas de aprendizagem ${ }^{8}$ e impõe o desenvolvimento de novas competências profissionais no ensinar, alicerçada num princípio teórico significativo: a autonomia do educando9

Quando em comparação com a aprendizagem por transmissão, quando se tem o professor no papel central, todas as evidências apontam para uma melhor produção de motivação, autonomia, curiosidade e pensamento crítico-reflexivo com o uso da pedagogia crítica de Paulo Freire, que desponta como maior ícone ${ }^{10}$, ou com o uso das mais atuais concepções de aprendizagem significativa e de aprendizagem experiencial ${ }^{11,12}$, com o educando no papel central. Assim, a partir de janeiro de 2013 o NEP passa a capacitar seus educadores com ênfase na facilitação com metodologias ativas de ensino-aprendizagem: a "Capacitação de Apoiadores Institucionais e de Educação Permanente em Saúde no Serviço".

A EP é uma perspectiva educacional que se centra primordialmente no processo de trabalho ${ }^{13}$ tendo como princípios: o compromisso institucional e social; a análise político-institucional; a adoção do trabalho como eixo do processo educativo; uma compreensão ampliada do espaço educativo; a construção coletiva de demandas, metas e soluções; a adoção da reflexividade, onde pensamento e ação coexistem e se influenciam mutuamente; a avaliação e monitoramento de processos e resultados; a articulação entre educação-gestão-cuidado; o compromisso com a liberdade de expressão; a 
viabilização dos pactos e acordos; a ênfase na multiprofissionalidade e interdisciplinaridade em todo o processo; o estabelecimento de relações entre pesquisa e formação com as instituições formadoras; e as interações com as instâncias de participação social em saúde ${ }^{14}$.

No segundo semestre de 2014 o SAMUFor começa a receber profissionais advindos de uma seleção pública da Secretaria Municipal de Saúde, que foram avaliados e capacitados em SBV antes de assumirem suas escalas de serviço. Esse processo coincidiu com a participação ativa do NEP SAMUFor na análise, discussão e publicação dos Protocolos Nacionais de Intervenção em Suporte Básico de Vida e em Suporte Avançado de Vida que ampliavam o conceito de Suporte Básico e Avançado de Vida, passando assim a nortear as atividades educacionais do NEP SAMUFor e as avaliações das mesmas.

Como resultado desse processo, em janeiro de 2015, o NEP recebe da gestão seu primeiro grande desafio: realizar uma avaliação diagnóstica da qualidade do atendimento de todos os profissionais do SAMUFor e da Central de Regulação das Urgências de Fortaleza (CRUFor), com prioridade para os profissionais condutores e técnicos de enfermagem, fato esse que motivou a realização desse estudo.

Em Educação Permanente em Saúde (EPS), as necessidades de educação continuada, educação em serviço e de desenvolvimento dos trabalhadores se pautam nos nós críticos do processo de trabaIho e nas necessidades da população que será assistida, respeitando as especificidades locais ${ }^{3}$. Assim, esse estudo se justifica pela possibilidade de, a partir dessa avaliação, se ter um retrato das competências já desenvolvidas por esses profissionais e com isso se poder alimentar a gestão administrativa e educacional com subsídios suficientes para um replanejamento de suas ações, em termos de EPS.

Embora o processo de analisar, apreciar, verificar e atribuir um juízo de valor, a algo ou a alguma situação, seja uma rotina no dia-a-dia do ser humano, o processo de avaliação no contexto ensinoaprendizagem sempre incomoda, tanto aos educadores quanto aos educandos, seja pelo juízo de valor recebido/emitido, seja pela subjetividade sempre envolvida de alguma forma.

Nesse contexto, é importante saber o propósito de cada avaliação que se faz. As avaliações podem ser feitas comparando desempenhos entre si ou a partir de critérios, respectivamente denominadas avaliações baseadas em norma e em critério ${ }^{15}$ : "essa avaliação critério-referenciada permite que o profissional conheça seus desempenhos considerados satisfatórios, orientando sua aprendizagem"16 (p. 109).

Na avaliação critério-referenciada parte-se de uma avaliação inicial, denominada avaliação diagnóstica, cuja intenção é conhecer os saberes e habilidades prévios dos participantes, seus diferentes pontos de partida individuais, para traçar as diferentes trajetórias rumo à meta de um perfil de competências desejado. É em relação a esse critério que os desempenhos individuais são comparados. A 
avaliação diagnóstica coloca em evidência potencialidades e fragilidades de cada profissional, para que o educador possa aproveitar aquelas primeiras para diminuir essas últimas.

Iniciativa inovadora, com a avaliação diagnóstica o NEP poderia ter subsídios para o replanejamento educacional da implementação da educação permanente no serviço, identificando individualmente o que cada profissional necessitava, envolvendo as necessidades da gestão e propondo processos educacionais que levassem os profissionais a atingir novos patamares cognitivos, afetivo-atitudinais e psicomotores em prol da melhoria do serviço no cuidado do paciente em situação de urgência. A relevância do estudo, tanto para a ciência quanto para os serviços e a sociedade, se apresenta pela pouca literatura existente acerca do uso da avaliação diagnóstica de competências profissionais em SBV para o planejamento da implementação da EP em um serviço pré-hospitalar.

Diante do exposto questiona-se: a avaliação diagnóstica das equipes pode ajudar no planejamento da implementação da educação permanente no serviço? Assim, é objetivo desse estudo relatar a experiência de avaliação diagnóstica de competências no suporte básico de vida prestado pelos condutores e técnicos de enfermagem do SAMU 192, em Fortaleza.

\section{Metodologia}

Trata-se de um estudo descritivo, de abordagem qualitativa, do tipo relato de experiência, sobre um processo avaliativo realizado no mês de fevereiro de 2015 com profissionais condutores e técnicos de enfermagem do SAMUFor, a fim de verificar as competências técnicas destes sobre suporte básico de vida. De um total de 286 profissionais ativos e vinculados ao SAMUFor (165 condutores e 121 técnicos), tinha-se trabalhando efetivamente em Unidades de Suporte Básico (USB) 193 profissionais (67,5\% do total), divididos em seis escalas, cada escala contando com 18 equipes de SBV (condutor e técnico de enfermagem), sendo esse o nosso universo de pesquisa.

Esse estudo seguiu as determinações da Resolução CNS № 510/2016 e da Carta Circular № 166/2018-CONEP/SECNS/MS, que dispensam a exigência prévia de registro e avaliação pelo sistema CEP/CONEP a estudos que versem sobre aspectos relacionados às práticas no serviço em que sejam respeitados os preceitos relacionados à privacidade dos participantes, a confiabilidade dos dados e a dignidade humana.

Em janeiro de 2015 foram realizados encontros para planejamento, com os educadores do NEP SAMUFor, onde foram decididos: o local onde ocorreria a avaliação, o processo de comunicação, convite e comparecimento, as competências a serem avaliadas, os instrumentos de avaliação com os respectivos escores, os equipamentos e materiais necessários, a preparação dos mesmos nas salas e a dinâmica diária de avaliação dos profissionais. 
A pesquisa ocorreu nas dependências do NEP SAMUFor, durante 9 dias, utilizando-se de três salas de educação permanente, onde ocorriam as avaliações, e de um auditório para 50 pessoas, onde era feito o acolhimento dos profissionais que chegavam. De acordo com a situação do plantão, os profissionais que não estavam em atividade eram liberados durante 90 minutos, de forma aleatória, sob decisão da Coordenação Médica da CRUFor, para se deslocarem em sua ambulância para a sede do NEP SAMUFor e participarem do processo avaliativo. Embora houvesse determinação para o deslocamento, participar do processo avaliativo era um ato voluntário, não havendo qualquer espécie de constrangimento ou determinação formal para o profissional.

Dessa forma, durante nove dias, os 193 profissionais em trabalho efetivo em USB compareceram, mas apenas 130 aceitaram voluntariamente participar da avaliação, sendo 70 condutores e 60 técnicos de enfermagem. Não foram registradas as razões para a recusa. As equipes eram chamadas por ordem de chegada, em grupos de três, para cada uma das três estações, de forma que ao final do dia se contemplavam as 18 equipes de USB de um plantão normal: 09h00 às 10 h00 (03 equipes rodiziando-se em três estações); $10 \mathrm{~h} 00$ às $11 \mathrm{~h} 00$ (mais 03 equipes); $11 \mathrm{~h} 00$ às $12 \mathrm{~h} 00$ (mais 03 equipes); $14 \mathrm{~h} 00$ às $15 \mathrm{~h} 00$ (mais 03 equipes); $15 \mathrm{~h} 00$ às $16 \mathrm{~h} 00$ (mais 03 equipes); e $16 \mathrm{~h} 00$ às $17 \mathrm{~h} 00$ (mais 03 equipes).

Dentro do universo de competências em SBV esperado para um profissional atuando no componente pré-hospitalar móvel de urgência da rede de urgência do município de Fortaleza, e considerando a ampliação do conceito de SBV feito pelo Ministério da Saúde em seus protocolos nacionais de SBV ${ }^{17}$, o grupo de educadores do NEP SAMUFor, composto de médicos, enfermeiros, técnicos de enfermagem e condutores, elencou algumas que julgou prioritárias a serem avaliadas, considerandose as necessidades da gestão e da população em situação de urgência: a) conhecer, executar e avaliar Check-list de enfermagem ao iniciar o plantão, como procedimento de segurança no SBV; b) conhecer, executar e avaliar Check-list veicular ao iniciar o plantão, como procedimento de segurança no SBV; c) conhecer, executar e avaliar biossegurança, segurança de cena e segurança do paciente (os 35 da segurança dos Protocolos de SBV do Ministério da Saúde); d) conhecer, executar e avaliar procedimentos de reanimação cardiopulmonar no adulto; e e) conhecer, executar e avaliar procedimentos de imobilização axial e apendicular no trauma.

Foram então montadas três estações, cada uma durando 15 minutos, com seus próprios roteiros de avaliação, avaliada por uma dupla de educadores e ocorrendo em uma sala individual, cada sala contendo os seus próprios equipamentos e materiais necessários: a) estação de manejo do paciente vítima de trauma, com paciente simulado (roteiro com 17 itens); b) estação de reanimação cardiopulmonar em adultos com uso do DEA, em manequim (roteiro com 13 itens); e c) estação de procedimentos de segurança, com entrevistas para os condutores sobre avaliação e segurança da cena 
(roteiro com 6 itens) e check-list veicular (roteiro com 36 itens); e entrevistas para os técnicos de enfermagem sobre check-list de equipamentos e materiais (um roteiro para cada equipamento/material): oxímetro de pulso (3 itens), glicosímetro (5 itens), DEA (5 itens), dispositivo bolsa-valva-máscara (3 itens), aspirador e oxigenioterapia ( 7 itens) e tensiômetro (4 itens). Nessa última estação avaliar as rotinas de chegada ao plantão (roteiro com 6 itens) e de biossegurança (roteiro com 6 itens) eram comuns aos condutores e técnicos de enfermagem.

Os casos, situações-problema, eram os mesmos para todos os profissionais, uma vez que o comando inicial era "faça como se fosse no seu plantão de hoje!" Para efeito de conceituação em "S" ou "PM", foram atribuídos escores para cada item crítico no roteiro de avaliação, de acordo com consenso entre os educadores do NEP sobre o grau de importância do item para a qualidade do atendimento, de forma que a soma dos escores em cada instrumento fosse dez $(10,0)$. Foi avaliado como "S" o profissional que obteve pontuação total mínima de sete $(7,0)$, obtida pela soma individual dos escores dos itens lembrados/realizados durante a avaliação. Na terceira estação, a pontuação era obtida pela média aritméticas das pontuações individuais de cada um dos 4 roteiros submetidos a condutores e 8 roteiros para os técnicos de enfermagem.

Quanto à dinâmica utilizada para a avaliação, o corpo de educadores escolheu a seguinte: a) acolhimento breve e inicial de todas as equipes de SBV antes de iniciar a estação propriamente dita, à medida que chegavam ao NEP e de forma individual, com foco na percepção pessoal do profissional dos próprios sentimentos envolvidos e na motivação pessoal/profissional para estar no processo; b) entrada da equipe na sala de Educação Permanente do NEP e explicação da dinâmica de avaliação pela dupla de avaliadores; c) apresentação de uma situação-problema a ser resolvida (a mesma para todos os participantes); d) desenvolvimento de habilidades do profissional para resolução da situaçãoproblema; e) checagem por cada educador, por meio do roteiro de avaliação da estação, dos itens críticos que foram executados pelo profissional; e f) fechamento da avaliação pela dupla de educadores, com conceituação do profissional em "Satisfatório" (S) ou "Precisa Melhorar" (PM).

\section{Resultados}

Já no acolhimento inicial dos profissionais, cujo foco era a percepção pessoal de sentimentos e motivação individuais para estar no processo avaliativo, a existência de conflitos interpessoais entre as equipes ou membros de uma mesma equipe, as condições inadequadas de trabalho ou falta intermitente de equipamentos e materiais, já ficavam patentes.

Submeteram-se à avaliação 130 profissionais, perfazendo-se um total de 368 avaliações, pois alguns profissionais não realizaram as três estações (chamados para ocorrências, desistências e resistências). Os 63 profissionais que compareceram e não se submeteram à avaliação não explicitaram 
seus motivos nem foi investigado os mesmos pelos educadores. Do total de 130 profissionais que fizeram a avaliação, somente 27 profissionais (20,8\% do total) obtiveram conceito satisfatório em todas as estações e 73 profissionais (56,1\% do total) obtiveram satisfatório somente em uma ou em nenhuma estação, conforme Tabela 1. Nessa mesma Tabela 1, percebe-se também, aparentemente, melhor qualificação de nossos condutores, em relação aos técnicos de enfermagem.

Tabela 1. Conceitos "Satisfatório" nas estações

\begin{tabular}{rcccc}
\hline SATISFATÓRIO & Condutor & Técnico de enfermagem & Total & \% do total de profissionais \\
\hline Nas três estações & 20 & 7 & 27 & $20,8 \%$ \\
Em duas estações & 15 & 15 & 30 & $23,1 \%$ \\
Em uma estação & 22 & 20 & 42 & $32,3 \%$ \\
Em nenhuma estação & 13 & 18 & 31 & $23,8 \%$ \\
Total de profissionais & 70 & 60 & 130 & $100 \%$ \\
\hline
\end{tabular}

O Gráfico 1 demonstra a participação das equipes no processo avaliativo durante os nove dias do processo, mostrando uma queda à medida que restavam menos profissionais a serem avaliados.

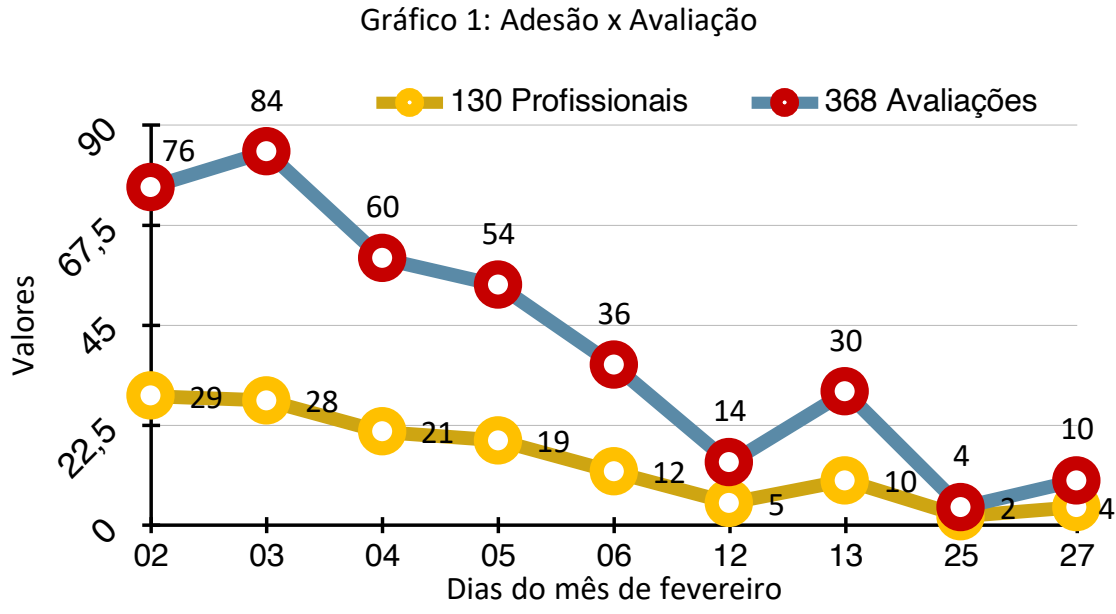

Na avaliação, depois da apresentação da situação-problema e desenvolvimento de habilidades do profissional para sua resolução, verificou-se que alguns profissionais ainda praticavam o que aprenderam no CEFUR à época que entraram no serviço pelo Programa S.O.S. Fortaleza. Eles não participavam de um processo educacional há mais de 20 anos. A seguir os incidentes críticos mais observados na avaliação diagnóstica:

- Estação de manejo do paciente vítima de trauma: equívocos na retirada de capacete; equívocos na indicação e na técnica de imobilização cervical com colar; equívocos na imobilização axial com imobilizador tipo KED; equívocos nos rolamentos e pranchamento.

- Estação reanimação cardiopulmonar (RCP) em adultos, com uso do desfibrilador externo automático (DEA): não solicitação de ajuda do Suporte Avançado de Vida (SAV) e/ou DEA; equívocos na realização das compressões torácicas; equívocos na realização da ventilação e técnica C-E; 
equívocos na checagem do pulso carotídeo; equívocos na colocação das pás do DEA; equívocos no revezamento após os ciclos de RCP.

- Estação de procedimentos de segurança: não informar o próprio nome ao paciente; não reconhecer macacão e botas como equipamentos de proteção individual (EPI); não checar glicosímetro (por achar que danifica a fita); não checar o dispositivo bolsa-valva-máscara (BVM); não checar o DEA corretamente; não checar a rede de gases corretamente; não checar o tensiômetro; não relatar a limpeza dos equipamentos; não relatar a checagem dos cabos e conexões dos equipamentos.

\section{Discussão}

Desde o Programa S.O.S. Fortaleza, os educadores do serviço sempre acreditaram no potencial humano nato de fazer conexões mentais entre o que sabe e o que percebe de novo e no potencial do erro como produtor de aprendizado. Com as atividades esvaziadas desde 2004, o NEP reinicia suas atividades em 2010 com um "Curso Permanente de Educação em Urgência" (extensivo, de abril a dezembro de 2010). O curso não finalizou, tendo evasão de 100\%. Assim, em dezembro de 2010 foi feito o primeiro e incipiente mergulho na tentativa de entender a educação de adultos: criou-se um curso de Capacitação de Tutores e Preceptores em Urgência Pré-hospitalar, com 24h/aula, baseado nos cursos de instrutores do curso de Suporte Básico de Vida da American Heart Association.

Em 2011 se inicia uma capacitação semipresencial em SBV que, promovida pelo Ministério da Saúde em parceria com o Hospital Alemão Oswaldo $\mathrm{Cruz}^{18}$, tem inscrição compulsória de todos os profissionais e finaliza também com altíssima taxa de evasão. Num ambiente de trabalho sem atualização dos profissionais quanto às mudanças que aconteciam nos protocolos internacionais de atendimento pré-hospitalar (APH) e buscando uma melhor gestão de aprendizagem, instituiu-se, em junho de 2013, uma rotina de reuniões semanais com todos os educadores para pensar estratégias de ensino-aprendizagem que motivassem a presença dos profissionais e lidasse com a pouca adesão e alta evasão existente.

Começou-se a pensar em metodologias ativas de ensino-aprendizagem, em problematizar o cotidiano de trabalho e em fatores de motivação do profissional. Assim, todas as atividades educacionais foram reformuladas, buscando-se ter como foco o diálogo sobre situações-problema a serem solucionadas/atendidas, seguidas de teorização pelo próprio educador e treinamento de habilidades.

Existe uma incipiência de trabalhos relacionados à avaliação diagnóstica de competências em profissionais do SAMU, realizada pelos seus núcleos de educação. Sabe-se que a educação permanente em serviços de urgência pré-hospitalar é decisiva para a qualidade assistencial ${ }^{19}$ e que faz parte dos objetivos dos Núcleos de Educação Permanente dos SAMU "incorporar atividades de pesquisa destinadas ao diagnóstico/avaliação do serviço"20 (p. 661), mas o desconhecimento dos profissionais 
sobre o conceito de educação permanente realmente parece afetar a implementação dessa estratégia $^{21}$, essencial na realidade do SAMU, posto que é "indispensável que os profissionais tenham conhecimento abrangente e direcionado para a realidade ${ }^{222}$ (p. 80).

As competências em SBV escolhidas, consideradas prioritárias a serem avaliadas, mostraram um instantâneo da situação e fizeram com que também se olhasse tanto para as possíveis causas quanto para as perspectivas de futuro, em termos de EP. Também fizeram com que se antevisse um provável cenário quanto às demais competências em SBV pediátrico, obstétrico, em saúde mental ou nas demais particularidades do SBV, como por exemplo na abordagem inicial ao paciente com IAM, AVC e politraumatismos, ou na crise asmática, assistência ao parto iminente etc.

Olhando para o passado, é provável que o resultado tenha sido consequência de um longo tempo sem processo de educação permanente e, consequentemente, sem reflexão crítica sobre os próprios processos de trabalho. Faz pensar também sobre a qualidade da formação dos profissionais condutores e técnicos de enfermagem para o trabalho atendimento de urgência em geral. Sem processos educacionais significativos, a desmotivação do profissional pode não o estimular à participação no constante processo de requalificação necessário ao trabalhador da urgência, complicando mais ainda a situação.

Olhando para o futuro, percebe-se uma longa jornada de motivação do profissional à EP como prioridade, já que a literatura mostra a dificuldade na adesão dos profissionais do SAMU aos processos de educação e que o gestor deve priorizar a qualificação profissional como parte de um processo de implementação de educação permanente ${ }^{23}$. A solicitação gestora para essa avaliação diagnóstica mostra o passo inicial para isso no SAMUFor.

O NEP SAMUFor sempre teve dificuldades em conseguir tanto essa presença em sala de aula dos profissionais fora de seu horário de trabalho quanto estratégias, junto à gestão, para que o processo se desse durante o plantão no SAMUFor. A experiência inicial com o ensino à distância ${ }^{18}$ em 2011 não diminuiu ou melhorou os índices de envolvimento educacional. O resultado desse processo de avaliação diagnóstica, como registro instantâneo das competências das equipes, foi o primeiro passo para um replanejamento da educação permanente no SAMUFor, problematizando as práticas individuais observadas.

Baseado nas diretrizes de implementação da Política Nacional de Educação Permanente ${ }^{5}$ e na Política Nacional de Educação Popular em Saúde ${ }^{24}$, nesse replanejamento realizado pelo NEP foram priorizados os seguintes princípios: a) o Diálogo, na convivência em grupos de aprendizagem (educando-equipe); b) a Amorosidade, onde o saber ouvir e a cooperação serão capacidades a serem desenvolvidas; c) a presença do Facilitador enquanto mediador da aprendizagem, responsável pela mediação entre os educandos e entre o educando e os conteúdos e atividades do curso; d) a 
Problematização em círculos de cultura, rodas de conversa, debriefings, oficinas com situações-problema e narrativas; e) a Construção Compartilhada do Conhecimento entre educandos e educadores, de forma a adequá-lo ao contexto regional, territorial e cultural local; f) a Conscientização e Reflexão Crítica: reconhecer-se como agente de transformação da realidade e não aceitação ingênua de padrões predefinidos (libertação/emancipação); g) a Emancipação na "re-busca" de novos significados e soluções; e h) a utilização de Ambiente Virtual que propicie uma Comunidade Virtual de Aprendizagem: espaços fora do tempo e espaço para comunicação assíncrona e compartilhamento de conteúdos disponíveis em áudios, vídeos, ilustrações e textos. Esse ambiente também propicia uma maior coesão da turma e esclarecimento de dúvidas sobre o conteúdo e sobre atividades do curso.

Na Figura 1 vemos a representação esquemática desses princípios educacionais ${ }^{25}$ :

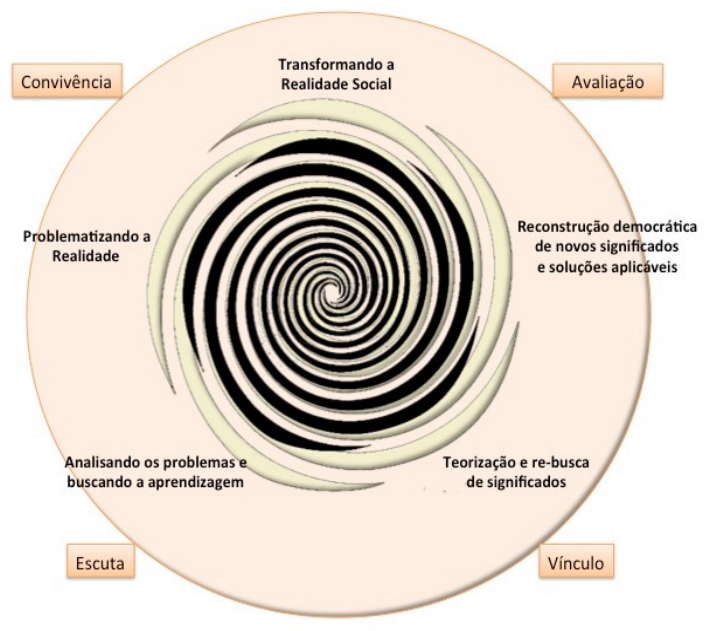

Figura 1. espiral de princípios educacionais do NEP SAMUFor. Fonte: NEP SAMUFor

Assim, o replanejamento obtido trouxe uma articulação entre a metodologia científica, a educação popular e de adultos e a problematização, que pode ser representada como uma espiral de princípios educacionais, representada em cinco "tempos", que se repetem como numa espiral, mas que nascem de um "tempo-base" oportuno e não cronológico, representado pelo círculo: a) "tempobase" contínuo de convivência com afeto/amorosidade, exercitando a escuta, criando vínculos, avaliando e autoavaliando-se continuamente no processo; b) tempo de observação/problematização da realidade pelo diálogo, em busca de novos significados; c) tempo de busca às possíveis causas dos problemas e elaboração de questões de aprendizagem; d) tempo de teorização e busca individual de possíveis soluções, "re-buscando" os significados obtidos; e) tempo de reconstrução compartilhada e democrática de novos significados e possíveis soluções que sejam aplicáveis; e f) tempo de saída à prática de transformação da Realidade Social. 
O estudo tem algumas limitações, como não conseguir tecer considerações sobre os reais motivos de muitos participantes não terem se submetidos aos processos de educação continuada no serviço, ou fora dele, nesses mais de 20 anos de trabalho. Também não se conseguiu verificar os possíveis fatores que contribuíram para os incidentes críticos mais observados na avaliação diagnóstica, nem o porquê da negativa à avaliação diagnóstica de 63 profissionais.

De outra forma, o estudo conseguiu fornecer subsídios suficientes para um total replanejamento educacional no NEP SAMUFor, pois percebeu-se quais competências básicas tinham que ser desenvolvidas e as situações cuja problematização poderia ser mais significativa em um ambiente educacional, agora utilizando metodologias ativas.

\section{Considerações finais}

Esse relato de experiência, que pode servir de referência para outros serviços, aumenta as evidências de que as ações de educação continuada e em serviço são insuficientes em promover mudanças efetivas e duradouras nos processos e práticas de trabalho, apontando para a educação permanente, baseada na problematização e na aprendizagem significativa, como fomentadora de tais mudanças.

Com a avaliação diagnóstica foram evidenciadas fragilidades do serviço no âmbito técnico-administrativo (formas de atendimento e fluxos de trabalho), mas também nos aspectos afetivo-atitudinais, pessoais ou interpessoais. Deste modo, foi possível definir as metas para o alcance da excelência nos cuidados referentes ao suporte básico de vida.

De posse dessas respostas, também replanejou-se a implementação da educação permanente no SAMUFor por meio de uma total reformulação das atividades educacionais e uma nova capacitação dos educadores, para que pudessem facilitar os processos educacionais com maior atenção às necessidades de aprendizagem detectadas na avaliação diagnóstica.

Isto posto, considera-se necessário apoio institucional para assegurar a continuidade dos processos de qualificação das equipes, mediante investimento em educação permanente e não em educação continuada ou em serviço, descontextualizadas da educação permanente. Isso fica mais patente quando se percebem os conflitos interpessoais entre equipes, ou internamente na equipe, condições inadequadas de trabalho e falta intermitente de equipamentos e materiais, contribuindo para a inadequada aplicação do aprendizado, e distorções das práticas, mesmo com processos bem estabelecidos de trabalho. 
Contribuição dos autores

Cláudio Roberto Freire de Azevedo participou na concepção e delineamento do trabalho, na obtenção, análise e interpretação dos dados; na discussão dos resultados, na redação do manuscrito e revisão crítica do seu conteúdo e na aprovação da versão final do manuscrito. Juliana Araújo de Medeiros participou na concepção e delineamento do trabalho, na obtenção, análise e interpretação dos dados; na discussão dos resultados e na aprovação da versão final do manuscrito. Julyana Gomes Freitas participou na revisão crítica do seu conteúdo e na aprovação da versão final do manuscrito. Wilcilene Oliveira dos Santos participou na obtenção, análise e interpretação dos dados e na aprovação da versão final do manuscrito. Cláudia Regina de Castro Lima participou na obtenção, análise e interpretação dos dados e na aprovação da versão final do manuscrito.

Agradecimentos

Núcleo de Educação Permanente do SAMU 192 - Regional Fortaleza; Universidade de Fortaleza

Direitos autorais

Este artigo está licenciado sob a Licença Internacional Creative Commons 4.0, tipo BY-NC (https://creativecommons.org/licenses/by-nc/4.0/deed.pt_BR).

\section{Referências}

1. Núcleo de Educação Permanente. Legislação SAMU 192 - Regional Fortaleza [Internet]. 2019 [cited 2021 Apr 16]. Available from: https://samu.fortaleza.ce.gov.br/index.php/o-samu-192-fortaleza/nucleo-deensino/legislacao

2. Núcleo de Educação Permanente. O SAMU 192 - Regional Fortaleza [Internet]. 2019 [cited 2021 Apr 16]. Available from: https://samu.fortaleza.ce.gov.br/index.php/o-samu-192-fortaleza

3. Farah BF. Educação Continuada/Permanente, Avaliação de Desempenho, Processo Demissional [Internet]. Juiz de Fora; 2016 [cited 2021 May 27]. Available from: https://www.ufjf.br/admenf/files/2019/03/Aula-9Educação-continuadapermanente-avaliação-de-desempenho-processo-demissional.pdf

4. Brasil M da SS de G do T e da E na SD de G da E em S. Política Nacional de Educação Permanente em Saúde [Internet]. Série B. Textos Básicos de Saúde Série Pactos pela Saúde 2006, v. 9. Brasília: Ministério da Saúde; 2009 [cited 2021 Apr 16]. 64 p. Available from:

http://bvsms.saude.gov.br/bvs/publicacoes/pacto_saude_volume9.pdf

5. Brasil M da S. Portaria GM/MS N 1996 , de 20 de agosto de 2007 [Internet]. 2007 [cited 2021 Apr 16]. Available from: http://bvsms.saude.gov.br/bvs/saudelegis/gm/2007/prt1996_20_08_2007.html

6. Peixoto LS, Gonçalves LC, Costa TD da, Tavares CM de M, Cavalcanti ACD, Elaine Antunes Cortez. Educação permanente, continuada e em serviço: desvendando seus conceitos. Enferm Glob [Internet]. 2013 [cited 2021 Apr 16];29:324-40. Available from: http://scielo.isciii.es/pdf/eg/v12n29/pt_revision1.pdf

7. Miccas FL, Batista SHS da S. Educação permanente em saúde: metassíntese. Rev Saude Publica [Internet]. 2014 [cited 2021 Apr 16];48(1):170-85. Available from:

http://www.scielo.br/scielo.php?script=sci_arttext\&pid=S003489102014000100170\&Ing=en\&nrm=iso\&tlng=pt

8. Lopes SRS, Piovesan ÉT de A, Melo L de O, Pereira MF. Potencialidades da educação permanente para a transformação das práticas de saúde. Com Ciências Saúde [Internet]. 2007 [cited 2021 Apr 16];18(2):147-55. Available from: https://pesquisa.bvsalud.org/portal/resource/pt/lil-484725

9. Berbel NAN. As metodologias ativas e a promoção da autonomia de estudantes. Semin Ciências Sociais e Humanas [Internet]. 2011 [cited 2021 Apr 16];32(1):25-40. Available from: http://www.uel.br/revistas/uel/index.php/seminasoc/article/view/10326

10. Alves MNT, Marx M, Bezerra MMM, Landim JMM. Metodologias Pedagógicas Ativas na Educação em Saúde. ID line Rev Psicol [Internet]. 2017 [cited 2021 Apr 16];10(33):339-46. Available from: https://idonline.emnuvens.com.br/id/article/view/659

11. Ruoff AB, Kahl C, Oliveira SN de, Melo LV de, Andrade SR de, Prado ML do. Aprendizagem Experiencial e Criação do Conhecimento: aplicações em enfermagem. REME Rev Min Enferm [Internet]. 2016 [cited 2021 Apr 16];20:e986. Available from: http://reme.org.br/artigo/detalhes/1122

12. Pisciottani F, Ramos-Magalhães C, Figueiredo AE, Pisciottani F, Ramos-Magalhães C, Figueiredo AE. Efeitos da aplicação periódica da simulação in situ para educação permanente em ressuscitação cardiopulmonar no 
contexto da hemodiálise. Enfermería Nefrológica [Internet]. 2020 [cited 2021 Apr 16];23(3):274-84. Available from: https://www.enfermerianefrologica.com/revista/article/view/4303

13. Haddad J, Roschke MA, Davini MC. Proceso de Trabajo y Educacion Permanente de Personal de Salud: reorientacion y tendencias en america latina. Educ Med Salud [Internet]. 1990 [cited 2021 Apr 16];24(2):136204. Available from: https://www.paho.org/Spanish/EMS/7515.pdf

14. Almeida J de. Princípios para Educação Permanente em Serviços de Saúde [Internet]. [São Paulo]: Instituto Sírio Libanês de Ensino e Pesquisa; 2017. Available from: https://www.researchgate.net/publication/351824154_PRINCIPIOS_PARA_EDUCACAO_PERMANENTE_EM_SE RVICOS_DE_SAUDE

15. Brito M do ST. Norma e critério de desempenho como parâmetros da avaliação da Aprendizagem. Estud em Avaliação Educ [Internet]. 1997 [cited 2021 Apr 16];(15):135-98. Available from: http://publicacoes.fcc.org.br/ojs/index.php/eae/article/view/2276

16. Braccialli LAD, Raphael HS, Chirelli MQ, Oliveira MAC de. Avaliação do estudante: no exercício de avaliação da prática profissional. Avaliação Rev da Avaliação da Educ Super [Internet]. 2008 [cited 2021 Apr 16];13(1):10118. Available from: http://www.scielo.br/scielo.php?script=sci_arttext\&pid=S141440772008000100006\&lng=en\&nrm=iso\&tlng=pt

17. Brasil M da SS de A à S. Protocolos de Suporte Básico de Vida [Internet]. 2a . Saúde M da, editor. Brasília: Ministério da Saúde; 2016 [cited 2021 May 24]. 482 p. Available from: http://bvsms.saude.gov.br/bvs/publicacoes/protocolo_suporte_basico_vida.pdf

18. Tobase L, Tomazini EAS, Teodoro SV, Piza NRG, Peres HHC. Ensino à distância na educação permanente em Urgência e Emergência. J Heal Informatics [Internet]. 2012 [cited 2021 Apr 16];4(Número Especial-SIIENF 2012):125-9. Available from: http://www.jhi-sbis.saude.ws/ojs-jhi/index.php/jhi-sbis/article/view/242

19. Teixeira A. Capacitação da equipe de saúde que atua nas unidades de suporte básico do samu de Florianópolis no atendimento à pacientes em parada cardiorrespiratória [Internet]. Florianópolis, SC; 2017 [cited 2021 Apr 16]. Available from: https://repositorio.ufsc.br/handle/123456789/173115

20. Ciconet RM, Marques GQ, Lima MAD da S. Educação em serviço para profissionais de saúde do Serviço de Atendimento Móvel de Urgência (SAMU): relato da experiência de Porto Alegre-RS. Interface - Comun Saúde, Educ [Internet]. 2008 [cited 2021 Apr 16];12(26):659-66. Available from: http://www.scielo.br/scielo.php?script=sci_arttext\&pid=S1414-32832008000300016\&lng=pt\&tlng=pt

21. El Hetti LB, Bernardes A, Gabriel CS, Fortuna CM, Maziero VG. Educação permanente/continuada como estratégias de gestão no Serviço de Atendimento Móvel de Urgência. Rev Eletrônica Enferm [Internet]. 2013 Dec 31 [cited 2021 Apr 20];15(4):973-82. Available from: http://revistas.ufg.br/index.php/fen/article/view/24405

22. Silva $A B$, Lopes $G M$, Batista $K M P$, Castro $M C$ da $S$. A educação permanente em saúde no serviço de atendimento móvel de urgência. Rev Sustinere [Internet]. 2018 [cited 2021 Apr 16];6(1):63-83. Available from: https://www.e-publicacoes.uerj.br/index.php/sustinere/article/view/31266/25720

23. Silva JG e, Vieira LJE de S, Pordeus AMJ, Souza ER de, Gonçalves MLC. Atendimento pré-hospitalar móvel em Fortaleza, Ceará: a visão dos profissionais envolvidos. Rev Bras Epidemiol [Internet]. 2009 [cited 2021 Apr 16];12(4):591-603. Available from: http://www.scielo.br/scielo.php?script=sci_arttext\&pid=S1415790X2009000400009\&lng=en\&nrm=iso\&tlng=pt

24. Pedrosa JI dos S. A Política Nacional de Educação Popular em Saúde em debate: (re) conhecendo saberes e lutas para a produção da Saúde Coletiva. Interface - Comun Saúde, Educ [Internet]. 2021 Nov 20 [cited 2021 May 24];25. Available from: http://www.scielo.br/scielo.php?script=sci_arttext\&pid=S141432832021000100400\&tlng=pt

25. Núcleo de Educação Permanente. Espiral de Princípios Educacionais do NEP SAMUFor [Internet]. 2021 [cited 2021 May 24]. Available from: https://sead.samu.fortaleza.ce.gov.br/mod/page/view.php?id=221\&forceview=1 


\section{ABSTRACT}

Objective: to report the experience of diagnostic evaluation of competencies in basic life support provided by SAMU drivers and nursing technicians, in Fortaleza. Methodology: a descriptive study, with a qualitative approach, of the type of experience report on competencies evaluation carried out with 193 professionals, in order to verify their technical competencies on basic life support, in February 2015, in 3 stations, contemplating the attendance to the trauma, cardiopulmonary resuscitation and safety procedures. Results: 130 professionals participated (67.4\% of the total); 63 were not available for evaluation. Those who attended completed a total of 368 evaluations, as some did not perform the three station (called for occurrences, withdrawals and resistance); only 27 (20.8\%) obtained a satisfactory concept in all station and $73(56.1 \%)$ obtained satisfactory only in one or no station. Better qualification of the drivers was perceived, in relation to the nursing technicians. Critical incidents were observed in the diagnostic evaluation. Final considerations: the weaknesses of the service were evidenced in the technical-administrative scope (forms of care and work flows), but also in the affective-attitudinal, personal or interpersonal aspects. As a consequence, a total reformulation of educational processes was planned in the implementation of permanent education in the service.

Descriptors: Educational Measurement; Continuing Education; Emergency Medical Services.

Keywords: Evaluation; Permanent Education; Popular Health Education; Competences; Urgency; Prehospital.

\section{RESUMEN}

Objetivo: reportar la experiencia de evaluación diagnóstica de competencias en soporte vital básico brindada por conductores y técnicos de enfermería del SAMU. Metodología: estudio descriptivo, con enfoque cualitativo, del tipo de relato de experiencia en evaluación de competencias realizado con 193 profesionales, con el fin de verificar sus habilidades técnicas en soporte vital básico, en febrero de 2015, en 3 estaciones, contemplando el trauma cuidados, reanimación cardiopulmonar y procedimientos de seguridad. Resultados: participaron 130 profesionales (67,4\% del total); 63 no estuvieron disponibles para evaluación. Los que asistieron completaron un total de 368 evaluaciones, ya que algunos no realizaron las tres estaciones (llamados por ocurrencias, retiros y resistencias); solo $27(20,8 \%)$ obtuvieron un concepto satisfactorio en todas las estaciones y $73(56,1 \%)$ obtuvieron satisfactorio solo en una o ninguna estación. Se percibió una mejor calificación de los conductores, en relación a los técnicos de enfermería. Se observaron incidentes críticos en la evaluación. Consideraciones finales: las debilidades del servicio se evidenciaron en el ámbito técnicoadministrativo (formas de cuidado y flujos de trabajo), pero también en los aspectos afectivo-actitudinales, personales o interpersonales. En consecuencia, se planificó una reformulación total de los procesos educativos en la implementación de la educación permanente en el servicio.

Descriptores: Evaluación Educacional; Educación Permanente; Servicios Médicos de Urgencia.

Palabras clave: Evaluación; Educación permanente; Educación Sanitaria Popular; Habilidades; Urgencia; Prehospitalario. 